\title{
Outbreak of zoonotic sporotrichosis in Southern Brazil
}

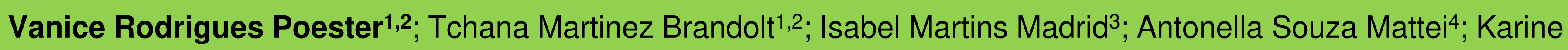
Ortiz Sanchotene1; Rossana Patricia Basso ${ }^{1,2}$; Gabriel Baracy Klafke1; Paula Portella Della Terra5; Anderson Messias Rodrigues ${ }^{5}$; Melissa Orzechowski Xavier ${ }^{1}$,

${ }^{1}$ Mycology Lab, Faculty of Medicine, Federal University of Rio Grande (FaMed-FURG), RS, Brazil; ${ }^{2}$ Post-graduation program in Health Science, FaMed-FURG, RS, Brazil ${ }^{3}$ Zoonosis control, Municipal Health Secretary of Pelotas, Pelotas, Brazil; ${ }^{4}$ University of Caxias do Sul; ${ }^{5}$ Cell Biology Division, Department of Microbiology, Immunology and melissaxavierfurg@gmail.com Parasitology, Federal University of São Paulo (UNIFESP), São Paulo, Brazil

\section{INTRODUCTION}

Given the geographic expansion of sporotrichosis in Brazil in the last decades and it zoonotic importance in public health, this study aimed to describe an outbreak of the disease in humans associated with the increase in feline sporotrichosis cases in the last five years.

\section{METHODS}

Retrospective study including all human and feline sporotrichosis cases diagnosed from October 2012 to October 2017 in two cities from south region of Rio Grande do Sul (RS), Brazil. All of them had Sporothrix spp. growth in mycological culture of clinical samples. Clinico-epidemiological data of the patients were evaluated. Database Analysis: Mycology Laboratory (FaMed-FURG, Rio Grande, RS, Brazil) and Zoonoses Control Center (CCZ - Pelotas, RS, Brazil).

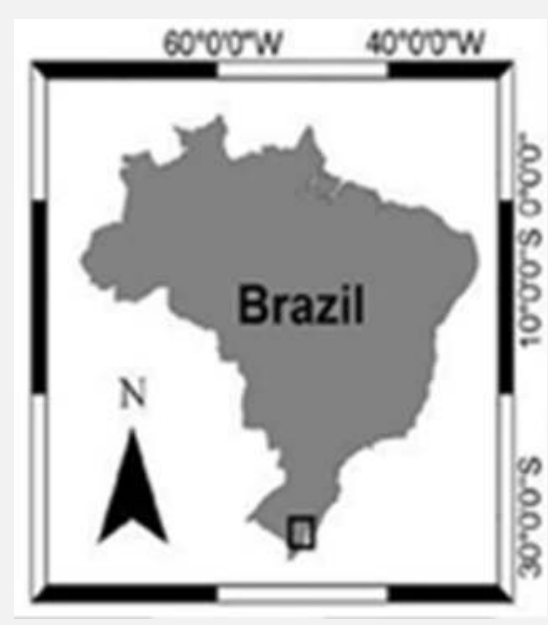

\section{RESULTS}

During the five-years studied, a total of $\mathbf{1 0 1}$ human sporotrichosis cases were diagnosed in the South region of RS, Brazil, corresponding to an average of 20 cases per year. Regarding feline sporotrichosis, $\mathbf{3 7 5}$ cases were diagnosed in the same period in south region of RS, corresponding to about 75 cases/year.

Table 1. Clinico-epidemiological data of human sporotrichosis $(n=101)$ diagnosed in the South region of RS, Brazil, among 2012 and 2017.

\begin{tabular}{lc}
\hline \multicolumn{1}{c}{ Variable } & Patients (\%) \\
\hline Gender & $63(62)$ \\
\hline Female & $38(38)$ \\
\hline Male & \\
\hline Age group & $06(7)$ \\
$<12$ years & $08(10)$ \\
$12-17$ & $48(60)$ \\
\hline $18-59$ & $19(23)$ \\
$>60$ & $20(20)$ \\
Missing & \\
\hline Clinical presentation & $39(42)$ \\
\hline Fixed & $35(38)$ \\
Lymphocutaneous & $17(19)$ \\
\hline Disseminate & $01(1)$ \\
Extracutaneous & $09(9)$ \\
Missing & $85(93)$ \\
\hline Source of infection & $06(7)$ \\
\hline Zoonosis & $10(10)$ \\
\hline Sapronosis & \\
Unknown & \\
\hline
\end{tabular}

Table 2. Clinico-epidemiological data from feline sporotrichosis $(n=375)$ cases diagnosed in south RS, Brazil, 2012 - 2017.

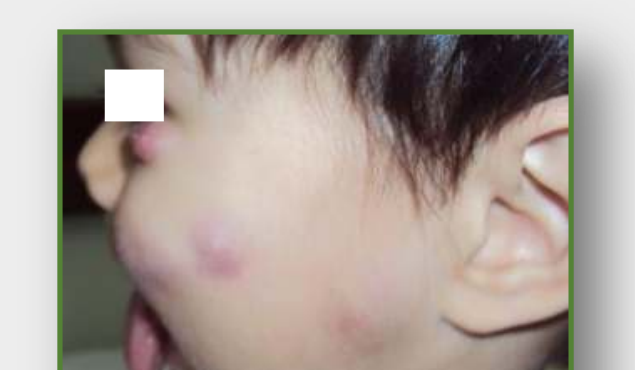

\begin{tabular}{|lc|}
\hline \multicolumn{1}{c}{ Variable } & Patients (\%) \\
\hline Gender & \\
\hline Male & $280(75)$ \\
\hline Female & $93(25)$ \\
Missing & $2(2)$ \\
\hline
\end{tabular}

Access to the street

\begin{tabular}{|cc|}
\hline Yes & $277(95)$ \\
\hline No & $15(5)$ \\
Missing & $83(45)$ \\
\hline
\end{tabular}

Reproductive status

\begin{tabular}{lc}
\hline Entire & $145(63)$ \\
\hline Castrated & $85(37)$ \\
Missing & $145(39)$ \\
\hline Clinical presentation & \\
Localized & $161(44)$ \\
Disseminated & $206(56)$ \\
Missing & $8(7)$ \\
\hline Outcome & \\
Recovery & $99(65)$ \\
Death & $54(35)$ \\
Missing & $222(69)$ \\
\hline
\end{tabular}

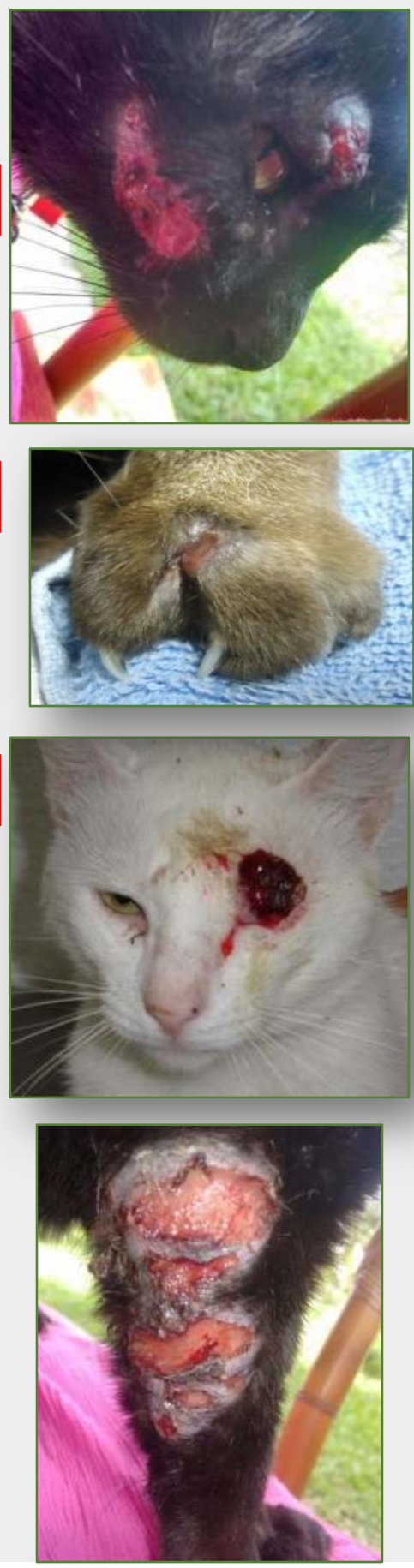

\section{CONCLUSION}

The increase in feline sporotrichosis cases, associated with the human sporotrichosis outbreak described, majority of them with zoonotic transmission, shows that the epidemiological situation of the disease in South region of RS, Brazil, is extreme worrying to public health, which may take severe proportions in future years. 